Article

\title{
An Integrated Analysis of GWR Models and Spatial Econometric Global Models to Decompose the Driving Forces of the Township Consumption Development in Gansu, China
}

\author{
Qianqian Zhao ${ }^{1,2}$, Qiao Fan ${ }^{1,3, *}$ and Pengfei Zhou ${ }^{4, *(D)}$ \\ 1 School of Economics, Lanzhou University, Lanzhou 730000, China; zhaoqq09@lzu.edu.cn \\ 2 Party School of Gansu Provincial Party Committee of the CPC, Gansu Institute of Public Administration, \\ Lanzhou 730070, China \\ 3 School of Economics and Social Studies, Chongqing University of Science \& Technology, \\ Chongqing 401331, China \\ 4 School of Economics and Management, Chongqing Normal University, Chongqing 401331, China \\ * Correspondence: fanq18@lzu.edu.cn (Q.F.); pengfeizhou@cqnu.edu.cn (P.Z.)
}

check for updates

Citation: Zhao, Q.; Fan, Q.; Zhou, P. An Integrated Analysis of GWR Models and Spatial Econometric Global Models to Decompose the Driving Forces of the Township Consumption Development in Gansu, China. Sustainability 2022, 14, 281. https://doi.org/10.3390/su14010281 Academic Editor: Angel Paniagua Mazorra

Received: 13 November 2021 Accepted: 18 December 2021 Published: 28 December 2021

Publisher's Note: MDPI stays neutral with regard to jurisdictional claims in published maps and institutional affiliations.

Copyright: (c) 2021 by the authors. Licensee MDPI, Basel, Switzerland. This article is an open access article distributed under the terms and conditions of the Creative Commons Attribution (CC BY) license (https:/ / creativecommons.org/licenses/by/ $4.0 /)$.

\begin{abstract}
The investigation of township consumption patterns has become highly significant in order to emphasize the importance of township consumption patterns in economic development and policy formulation. To attain township consumption development in underdeveloped areas is a significant way to meet the general criterion of "rich life" under China's Rural Revitalization strategy. The primary objective of this study is to evaluate the driving forces that contribute to the development of township consumption in underdeveloped areas such as Gansu Province, China, and then scientifically design and implement a strategy for township consumption development in Gansu, all of which are related to the broader interests of rural revitalization. The study used 1233 township data of Gansu Province, China. The study integrated geographically weighted regression (GWR) and a spatial econometric global (SEG) model for data analysis and interpretation. The integration of these two models can comprehensively capture both spatial heterogeneity and spatial independence concurrently. First, we conducted integrated analyses of GWR and SEG models using consistent settings of spatial weight matrix elements, with GWR focusing on spatial heterogeneity and SEG models on spatial spillover. Second, the permanent resident population, the number of financial institution outlets, the types of townships, and the characteristics of townships had a substantial significant effect on the development of township consumption in Gansu, China. In addition, the ratio of residents with access to basic medical insurance was found to be negatively significant. The revitalization strategy for township consumption in Gansu Province, China should prioritize increasing the permanent resident population of townships, accelerating the development of township urbanization, accelerating the construction of township consumption infrastructures, and strengthening financial support from township financial institutions.
\end{abstract}

Keywords: rural revitalization; spatial economic models; township consumption; China

\section{Introduction}

Globally, rural population shares are dropping, and calls for rural revitalization have been raised [1,2]. Rural revitalization has become a major political concern in China as a result of economic transition and changes in urban-rural interaction. China's economic reforms, which began in 1978, have had a profound effect on the country's economic growth and living standards. They have, however, increased earnings and living standard disparities between urban and rural areas. Hundreds of millions of people have migrated from rural areas to urban areas, depleting rural human resources. Thus, as the central government places a high premium on rural vitalization, it is crucial to launch a broad conversation about what is required for rural revitalization at its most fundamental level, 
the township [3-5]. Rural revitalization is primarily concerned with increasing productivity, rural development, raising living conditions, keeping townships clean and tidy, and ensuring effective governance. However, the manner in which this is executed at the village level has received insufficient attention $[2,6]$.

Prosperity is one of the five principles of China's rural revitalization policy [7]. Townships are grassroots political groups that exist throughout China's vast rural areas and serve as vital connectors between counties and villages. Township prosperity is highly dependent on the development of township consumption [8]. The development of township consumption economies is the heart and driving force of rural consumption economies in China, and the degree and extent of township consumption in underdeveloped areas determine the rural consumption economy's lower limit. Gansu is one of China's most backward provinces, and township consumption is slower than in other regions [9-11]. Thus, accurately identifying the primary drivers of township consumption development in Gansu, and then scientifically designing and implementing a strategy for township consumption development in Gansu Province, China, all bear on the overall interests of rural revitalization and the construction of a moderately prosperous society.

The following potential influencing factors on township consumption development have been explored extensively in the literature. In general, the three major components of gross domestic product (GDP) by expenditure method are final consumption, total capital formation, and net export. For small townships, a relative lack of imports and exports, as well as a low level of fiscal revenue and expenditure, will constrain the scale of government investment; therefore, stimulating the development of the township consumption economy will be critical for leveraging inclusive economic growth in these regions. Economic research has always been focused on consumer behavior $[12,13]$. Consumer behavior studies in regional economics are more concerned with the evolution of the consumption economy at the micronational or provincial level, and at the micronational or county level, than with individual consumer behavior at the micro-level. Recent research on macro- or meso-level consumption economic development has emphasized not only the level, scale, structure, and influencing elements of consumption economic growth, but also the heterogeneity of regional consumption economic development and its influencing variables [14-16].

Generally, we incorporate information on the driving causes of township consumption development in undeveloped areas as a meso-level study that examines the consumption development of towns and ethnic townships and deconstructs their driving forces. We examined the literature for a piece of theoretical evidence indicating which aspects could be crucial in influencing township consumption development. Unfortunately, we discovered few essays that specialized in study of the rise of township consumption in undeveloped areas. However, if we expand our view to include influencing factors at the regional level of consumption development, we discover several pieces of evidence. Generally, it is thought that regional consumption is influenced by three dimensions: demand, supply, and circulation [17]. Among them, supply side factors include local capital accumulation and government and private sector investment, demand side factors include regional income level and population size, and circulation side factors include the scale and speed of local business circulation and the development of circulation infrastructure [18]. The driving factors of regional consumption development are shown in Figure 1.

The population is a critical demand factor in promoting regional consumption growth [19]. The size, quality, structure, and migration rules of the local population will all have a substantial impact on regional consumption, either directly or indirectly. Other demographic variables such as consumption patterns, urbanization rates, and employment conditions will all have a substantial impact on the level of local consumer economic growth [20]. Regional income is another significant element determining the growth of regional consumption [21]. Consumption, according to classical consumption theory, is often determined by income, which might be permanent, relative, or disposable. In general, greater regional residents' ownership of the real estate, securities, and other assets leads 
to stronger local consumption development, whereas increased medical, education, and housing expenditure turns into worse regional consumption development.

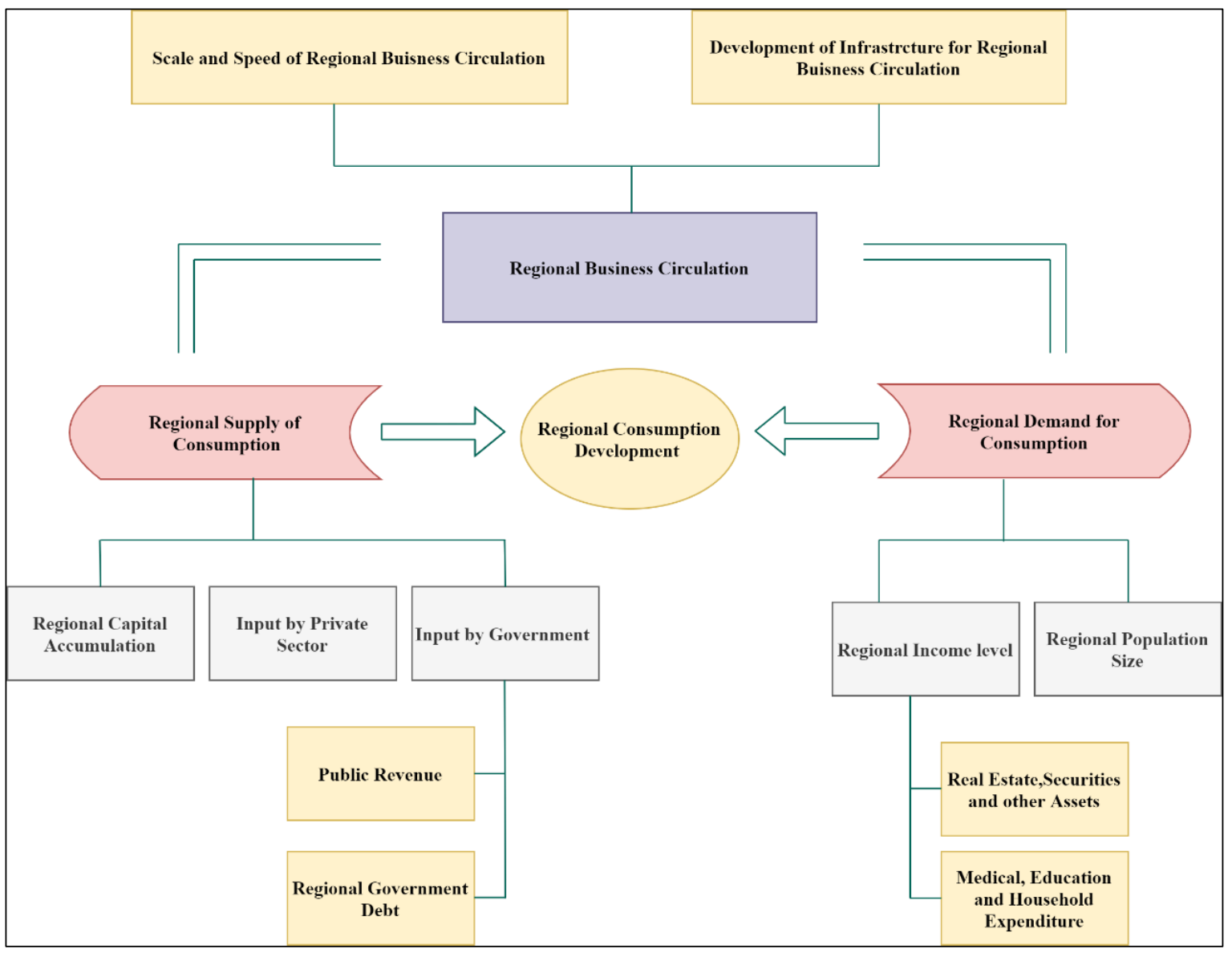

Figure 1. The driving factors of regional consumption development.

Regional consumption growth will be constrained by the capacity of local consumption supply, which is primarily determined by the primary and new capacity of regional consumption supply. Both economic development and capital accumulation at the local level determine the underlying strength of regional consumption supply. A higher degree of regional economic development and capital accumulation indicates a larger scale of consumption supply capital accumulation, which can ensure local consumption's main supply capability. Regional supply capacity is also dependent on newly increased consumption supply capacity within the region, which is primarily driven by the private sector and public sector investment [22-24]. Private sector investment is relatively low in townships in underdeveloped areas, and government funding accounts for the majority of the additional supply capacity for regional consumption. Local government investment is primarily funded by public revenue, productive debt, and transfer payments from a superior authority, all of which have a positive effect on regional consumer supply capacity. A smooth and efficient business environment is critical for the growth of local consumption. First, the rapid expansion of the volume and speed of regional business circulation will benefit regional consumption development by lowering search fees and transportation expenses, increasing the radius, frequency, and scale of transactions, and improving the transaction methods and environment [23]. Simultaneously, the expansion of regional business circulation will be critical in optimizing the structure of local consumption. Second, the expansion of regional business circulation infrastructure will have a substantial impact on regional consumption growth. Notably, increasing the number of financial institutions' outlets will stimulate and optimize residents' consumption by increasing financial institu- 
tions' operational efficiency [25], providing more convenient and diverse financial products, and providing sufficient financial credit and services, all of which will contribute to the development of the township consumption economy. While the majority of studies have focused on consumer behavior, decomposition of township energy consumption, and township enterprises, there is a lack of studies on the decomposition of township consumption development, especially in developing countries. This study will be significant from the perspective of a developing country such as China's underdeveloped areas.

This study investigates the driving forces behind township consumption development in Gansu Province, China, using data from 1233 townships from the third national agricultural census of Gansu, China. The study has taken total retail sales of consumer goods as a response variable to evaluate the effect of decomposition of township consumption development on explanatory variables including economic characteristics (government revenue, permanent resident population, public expenditure, township total assets, commodity market trading volume, number of financial institution outlets, and the percentage of residents covered by endowment and medical insurance) and policy characteristics (township types, township attributes, historic revolutionary areas, and border areas). The current study employs an integrated framework of the GWR and a spatial econometric global model to analyze and interpret the collected data. GWR models emphasize spatial heterogeneity in the classic sense, whereas spatial econometric global models emphasize spatial dependence and spillover effects. In this analysis, we seek to develop a unified framework for simultaneously investigating spatial heterogeneity and spatial relationships. This work will offer a marginal contribution not only to the theory of driving factors' decomposition in the development of township consumption in underdeveloped regions but also to promoting some integrated research between GWR models and spatial econometric global models. The paper is organized as follows: Section 2 provides a methodological framework including integration of the GWR and spatial econometric global model. Section 3 gives a brief description of data sources and variables. Section 4 demonstrates model estimations and calibration. Finally, Section 5 summarizes the major findings and policy recommendations.

\section{Methodological Framework for Driving Force Decomposition of Township Consumption Development}

This study intends to decompose the driving force of township consumption development using a new integrated analysis of GWR and spatial econometric global models. In the traditional spatial analysis, researchers usually employ GWR models and spatial econometric global models to explain the laws of spatial heterogeneity and spatial dependence separately. However, we can integrate these two types of models by the consistent settings of elements of the spatial weight matrices.

\subsection{GWR Models: A Spatial Econometric Local Analysis}

Geographically weighted regression (GWR) is a local spatial regression analysis with changeable parameters [26-28]. This approach originates from traditional regression, which follows the Gauss-Markov theorem, and emphasizes the need for setting different parameters for the same explanatory variables in the local model at different points due to spatial heterogeneity. In essence, we may estimate these characteristics using multiple samples from distinct sampling procedures within the constraints of a uniform fixed or adaptive spatial bandwidth and a centralized preset kernel function. If the spatial bandwidth is adaptive, we can use a set number of distinct samples to estimate the parameters for the local model at each point [29].

There are two types of benchmark models in the family of the GWR models, a semiparametric GWR model or mixed GWR model. We use the former semi-parametric form and set the benchmark model as the following Equations (1) and (2).

$$
\begin{gathered}
y=X_{g} \beta_{g}+X_{l} \beta_{l}\left(\mu_{i}, v_{i}\right)+\eta \\
W_{i}=\operatorname{diag}\left\{W_{i l}\right\}
\end{gathered}
$$


In Equation (1), $y$ is the dependent variable, and $\eta$ is the random disturbance terms; $X_{g}$ and $X_{l}$ are vectors indicating the global and local explanatory variables, respectively; $\beta_{g}$ are exogenous parameters of the global variables, while $\beta_{l}\left(\mu_{i}, v_{i}\right)$ are exogenous parameters of the local variables; $\left(\mu_{i}, v_{i}\right)$ represents the spatial location information, where $\mu_{i}$ and $v_{i}$ are the longitude and the latitude of the local point $i$. In Equation (2), $W_{i}$ is the spatial weight matrix for the local model of the point $i$; $\operatorname{diag}\{$.$\} means the matrix is diagonal and$ with elements only on the main diagonal; $W_{i j}$ are the diagonal elements of $W_{i}$, and their values indicate spatial effects from all the sampled neighbor points $l$ at the point $i$ to the local point $i$ [15].

As shown in Equation (1), the semi-parametric GWR model considers both the global and local variables in a single model. We can degrade this benchmark semi-parametric model to other models. It will be a mixed GWR model if $\beta_{g}$ is equal to zero, while a traditional regression model if $\beta_{l}\left(\mu_{i}, v_{i}\right)$ is equal to zero. Meanwhile, we can select the variables in the model of Equation (1) in two ways: from global to local, or from local to global. Usually, weighted least squares is used to estimate their parameters, and $W_{i}$ in Equation (2) will be used as the weights in the parameters' estimation process of the local model of the point $i$.

\subsection{General Nesting Spatial Model and Its Degradation Models: A Spatial Econometric Global Analysis}

In comparison to the popular spatial econometric local analysis in geographical research, the spatial econometric technique most frequently employed in economics is a global analysis [30]. This thorough spatial econometric analysis emphasizes the importance of obtaining a unified parameter for the same explanatory variable by concurrently developing a unified model employing all the sample data. There are also two benchmark models in the spatial econometric global analysis [31], the non-spatial model (NSM) with characteristics of the traditional regression model, and the general nesting spatial model (GNSM) [32]. The latter is as shown in Equation (3).

$$
y=\rho W y+X \beta+W X \theta+\mu, \mu=\lambda W \mu+\varepsilon
$$

Here, $y$ is the dependent variable and $X$ is the vector of explanatory variables, respectively; $\mu$ and $\varepsilon$ are both disturbance terms, where $\varepsilon$ follows a normal distribution with zero mean and constant variance; $\rho, \beta, \theta, \lambda$ are exogenous parameters, where $\rho$ and $\lambda$ are spatial correlation coefficients; $W=\left\{W_{i j}\right\}$ is the spatial weight matrix, and $W_{i j}$ indicates a spatial influence from region $j$ to region $i$ [33].

The GNSM considers not only the spillover effects from the dependent variables of the neighbor regions $(W y)$ but also the spillover effects from both the explanatory variables and disturbance terms of the neighbor regions $(W X \& W \mu)$. If all the exogenous parameters except $\beta$ in Equation (3) are equal to zero, we can degrade the model to the NSM, $y=X \beta+\varepsilon$. There are six other degradation models between the GNSM and NSM, and their shorthand name and degrading conditions are as shown in Figure 2 [31,34].

The global spatial econometric analysis begins with the GNSM or NSM benchmark model and ends with an ideal model by eliminating or adding variables to the benchmark model. We often choose the optimal model using hypothesis tests such as the LR, LM, and Wald tests [33,35], where the null hypotheses are always the degrading conditions, as seen in Figure 2. Generally, the chosen model can be used to describe the geographical dependence between the dependent and explanatory variables, as well as economic interpretation, structural decomposition, and prediction. 


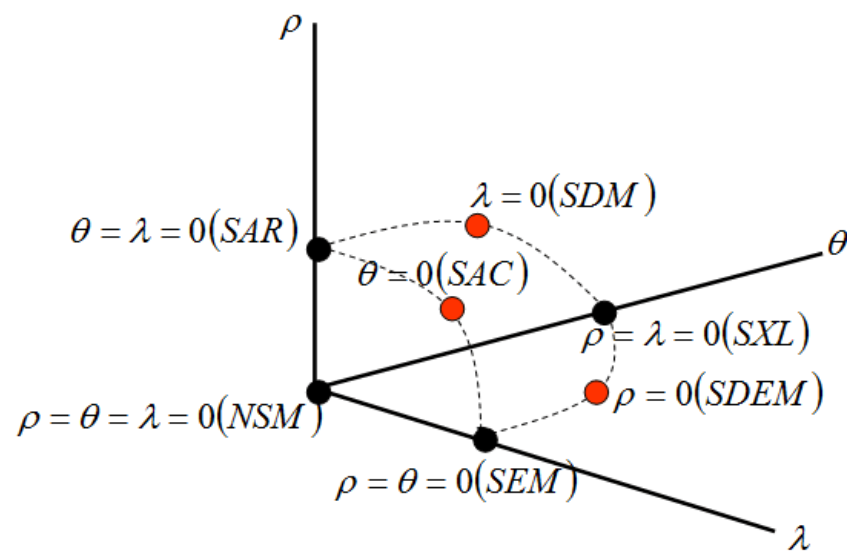

Figure 2. Seven degradation models of GNSM and their degrading conditions.

2.3. Integration of Spatial Econometric Local and Global Analysis: Through the Consistent Settings of Elements of the Spatial Weight Matrices

The spatial weight matrix is fundamental in both local and global spatial economic analysis. However, we are unable to expertly reconcile the conclusions drawn by these two methodologies due to the different setup patterns of the spatial weight matrix elements. At each point, the spatial weight matrices for GWR models are unique, and researchers often calculate their aspects using kernel functions and spatial position information, which is typically represented by the longitude and latitude of the sampled points [36]. Additionally, the GWR models' kernel functions are often Gaussian, bi-square, or tri-cube. The global analysis's spatial weight matrices are frequently the same for all sampling points, and their elements are determined by neighborhood relationships, distance, and economic or social scale [37-39]. Additionally, we use kernel functions to compute the components of the spatial weight matrices in the global analysis, and their forms can be Gaussian, bi-square, or other.

If we ensure that the determination patterns of the elements of their spatial weight matrices are consistent, there will be an ideal opportunity to integrate spatial local and global analysis. The primary considerations are as follows: first, ensuring that we employ the same number of originating peripheral sites in both types of analysis to explore the regularity or heterogeneity of spatial dependency for each local destination point. Second, ensuring that we utilize the same kernel function to determine the spatial impacts originating from each destination point's periphery points. Third, verifying that we adhere to the same patterns when defining location information and calculating distances between two sites. Based on these considerations, the following three procedures can be used to conduct an integration analysis between spatial econometric local and global models.

First, in the GWR models, the elements of the spatial weight matrices are calculated using an adaptive spatial bandwidth and a bi-square kernel function, as seen in Equation (4).

$$
W_{i l}=\left[1-\left(\frac{d_{i l}}{h}\right)^{2}\right]^{2}, 0<d_{i l} \leq h
$$

In Equation (4), $h$ is the adaptive spatial bandwidth, and $d_{i l}$ is the distance from the point $l$ to the point $i$. It needs to be noted that (a) the length is calculated by the latitude and longitude spherical distance; (b) the point $i$ is one of the destination points, $i=1,2, \cdots, n$; (c) the point $l$ is one of the sampled peripheral points at the point $i$ whose spatial distance to the point $i$ is less than $h$. From Equation (4), the outer points will not be included under the analysis framework at the point $i$ when their distance to the point $i$ is bigger than $h$. That is, for a point $m$, if $d_{i m}>h$, there will be $\left\{W_{i m}\right\}=\varnothing$, and $\varnothing$ is the symbol of an empty set.

Second, we select the optimal spatial bandwidth by the criteria of $A I C_{c}$, and denote this bandwidth as $h_{G W R}$. 
Third, in the global analysis, the elements of the spatial weight matrix are calculated based on the bi-square kernel function, the latitude, and longitude spherical distance, and the selected optimal bandwidth, as shown in Equation (5). In Equation (5), $W_{i j}^{g}$ are the elements of the spatial weight matrix $(W)$ used in the spatial econometric global analysis, and $d_{i j}$ is the spatial distance between the point $i$ and all other spatial units $j$.

$$
W=\left\{W_{i j}^{g}\right\}, W_{i j}^{g}=\left\{\begin{array}{l}
{\left[1-\left(d_{i j} / h_{G W R}\right)^{2}\right]^{2}, 0<d_{i j} \leq h_{G W R}} \\
0, i=j \text { or } d_{i j}>h_{G W R}
\end{array}\right.
$$

From Equations (4) and (5), we can obtain $l \in j$. The elements of the spatial weight matrices in the GWR models and the global analysis will have a similar relationship. That is, the non-zero elements of the $i$ th row of the global model's spatial weight matrix will correspond to the diagonal elements of the spatial weight matrix in the GWR models at point $i$. It is necessary to keep in mind that the spatial weight matrix used in the global analysis should be row-stochastic, whereas the spatial weight matrices used in the GWR models do not need to be standardized.

\section{Data Sources and Variables Descriptions}

This study considers Gansu, China as a case study to analyze the factors that influence township consumption in undeveloped areas through an integrated analysis of spatial local and global data. Gansu is one of China's 31 provinces and is a backward province in northwest China with 1233 townships [40]. Our study analyzed the most recent data from the 1233 towns included in Gansu, China's third national agricultural census, from 1 January 2016 to 31 December 2017. The study area is shown in Figure 3.

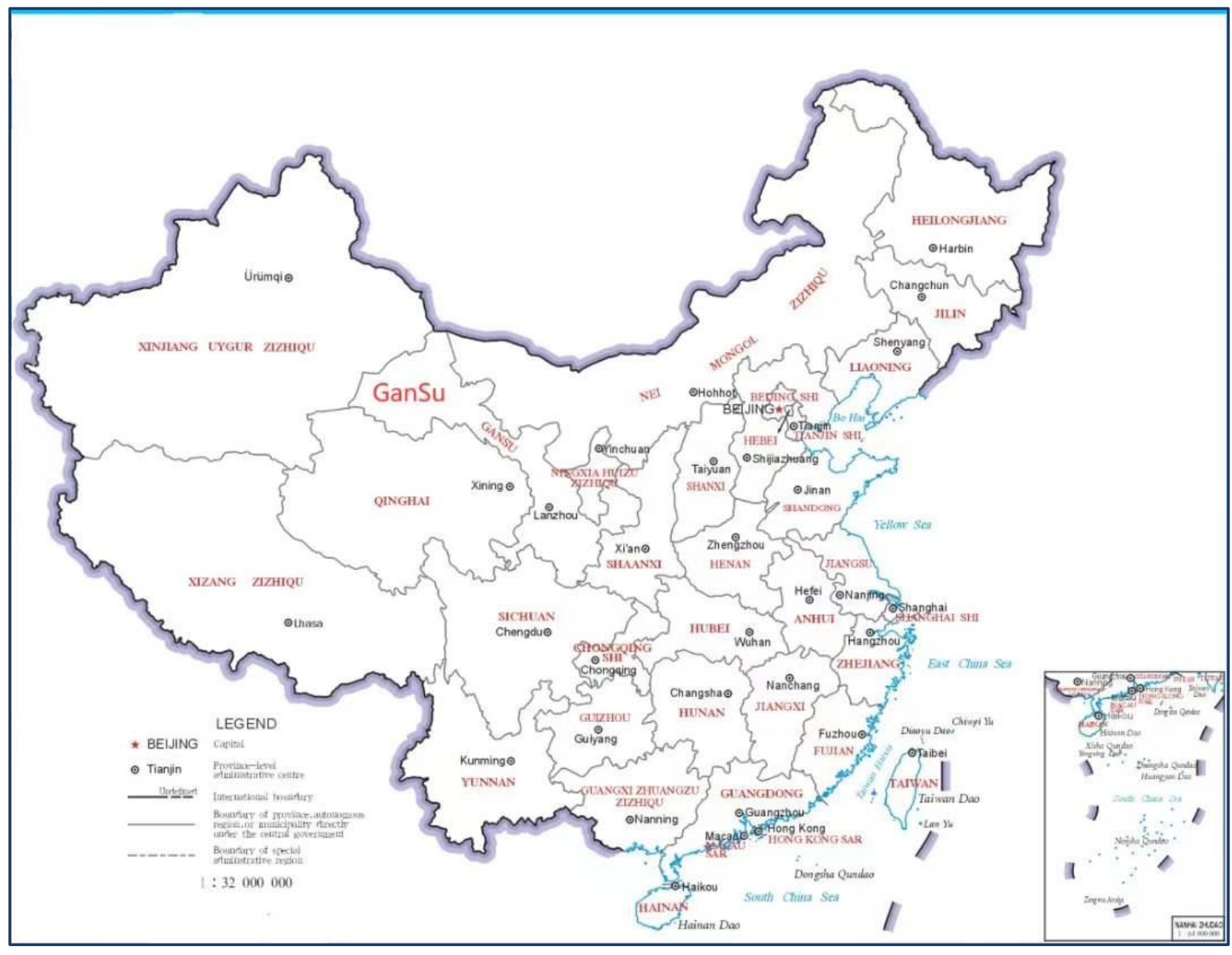

Figure 3. Study area, Gansu Province, China. 
As shown in Table 1, the indicator of total retail sales of consumer goods is the dependent variable that characterizes the level of township consumption development in Gansu, China, while the other 11 indicators are potential explanatory factors that will be chosen later via hypothesis tests.

Table 1. Indicators and corresponding codes of the data in the "township census table" of Gansu.

\begin{tabular}{|c|c|c|c|c|}
\hline & & \multicolumn{2}{|l|}{ Name of Indicators } & $\begin{array}{l}\text { Corresponding } \\
\text { Census Codes }\end{array}$ \\
\hline \multirow{13}{*}{ Explanatory Variables } & \multirow{8}{*}{$\begin{array}{c}\text { Economic } \\
\text { Characteristics }\end{array}$} & Permanent Resident Population & $\mathrm{X} 1$ & Z18 \\
\hline & & Government Revenue & $\mathrm{X} 2$ & $\mathrm{Z} 20$ \\
\hline & & Public Expenditure & X3 & $\mathrm{Z} 21$ \\
\hline & & Township Total Assets & X4 & $\mathrm{Z} 22$ \\
\hline & & Trading Volume of Commodity Market & X5 & Z37 \\
\hline & & $\begin{array}{l}\text { The Ratio of Residents Covered by Basic } \\
\text { Endowment Insurance }\end{array}$ & X6 & Z60 \\
\hline & & $\begin{array}{l}\text { The Ratio of Residents Covered by Basic } \\
\text { Medical Insurance }\end{array}$ & X7 & Z61 \\
\hline & & Number of Outlets of Financial Institutions & X8 & Z65 \\
\hline & \multirow{5}{*}{ Policy Characteristics } & Township Types & X9 & Z01 \\
\hline & & Township Attributes & X10 & Z02 \\
\hline & & Old Revolutionary Areas, & X11 & Z04 \\
\hline & & Border Areas, & & Z05 \\
\hline & & and Ethnic Minority Areas & & Z06 \\
\hline Depender & t Variable & Total Retail Sales of Consumer Goods & $\mathrm{Y}$ & Z35 \\
\hline
\end{tabular}

We did not treat the data for the variables listed above in the same way. First, the data for the main variables of $Y, X 1, X 2, X 3, X 4, X 5$, and X8 are taken straight from Gansu, China's third national agricultural census. Second, we estimate the ratio of residents covered by basic endowment insurance to the total number of residents covered by basic endowment insurance divided by $\mathrm{X} 1$, as well as the rate of residents covered by basic medical insurance. The total numbers of residents covered by basic endowment insurance and the total number of residents covered by basic medical insurance are both derived directly from Gansu, China's third national agricultural census. It is necessary to note that if the two ratios above are more significant than 1 , they will be filtered to 1 . Third, we treated the data from X9, X10, and X11 differently. For township types, we define X9 as 1 if the relevant townships are principal towns, and zero if they are not. Additionally, we set X10 to 1 if the necessary towns are located near the seat of a superior authority, and to zero if they are not. Indicators of old revolutionary areas, border areas, and ethnic minority areas will have a value of 1 if the respective townships are old revolutionary areas, border areas, or ethnic minority areas, and zero if they are not. The statistics required to define X9, X10, and X11 are likewise taken directly from Gansu, China's third national agricultural census.

Additionally, we collected the latitudes and longitudes of all 1233 townships in Gansu, China using the XGEOCODING V2 BETA software, which can extract spatial data in bulk from Baidu or Google Maps [41,42]. These latitudes and longitudes are critical for determining the spatial weight matrix elements in both the spatial local and global analysis, and we extracted them at 1:13 p.m. on 11 August 2021.

\section{Models' Estimation and Calibration}

\subsection{The Estimated Results for the Benchmark Model and Their Robustness}

We proceed by decamping the driving factors of the township consumption development from the benchmark NSM, and this benchmark model does not consider the spatial spillover effects from the neighborhood regions. Based on the variables listed in Table 1 and the data of their corresponding indicators, we estimated the NSM in Figure 2 by the Stepwise Regression Toolbox of MATLAB R2019a [43], and the results are as shown in column 2 in Table 2 . It reveals that, at the significance level of $1 \%$, five factors, including X1 
and $X 7$ to $X 10$, are significant to the township consumption development in the NSM. In detail, X7 has a negative influence, while the other four factors have a positive impact on the development of township consumption.

Table 2. Estimated results of the benchmark model and its extension models.

\begin{tabular}{|c|c|c|c|c|c|c|c|}
\hline & $\begin{array}{c}\text { The } \\
\text { Benchmark } \\
\text { Model }\end{array}$ & $\begin{array}{c}\text { Extension } \\
\text { Model } 1 \\
\text { (X6) }\end{array}$ & $\begin{array}{c}\text { Extension } \\
\text { Model } 2 \\
\text { (X4) }\end{array}$ & $\begin{array}{c}\text { Extension } \\
\text { Model } 3 \\
\text { (X2) }\end{array}$ & $\begin{array}{c}\text { Extension } \\
\text { Model } 4 \\
\text { (X5) }\end{array}$ & $\begin{array}{l}\text { Extension } \\
\text { Model } 5 \\
\text { (X3) }\end{array}$ & $\begin{array}{c}\text { Extension } \\
\text { Model } 6 \\
\text { (X11) }\end{array}$ \\
\hline Constant & $\begin{array}{l}15,667.28 \\
\left(3.90^{* * *}\right)\end{array}$ & $\begin{array}{l}15,652.78 \\
\left(3.89^{* * *}\right)\end{array}$ & $\begin{array}{l}15,714.43 \\
\left(3.91^{* * *}\right)\end{array}$ & $\begin{array}{l}15,830.74 \\
\left(3.93^{* * *}\right)\end{array}$ & $\begin{array}{l}15,819.76 \\
\left(3.93^{* * *}\right)\end{array}$ & $\begin{array}{l}15,653.15 \\
\left(3.89^{* * *}\right)\end{array}$ & $\begin{array}{l}15,867.98 \\
\left(3.95^{* * *}\right)\end{array}$ \\
\hline $\mathrm{X} 1$ & $\begin{array}{c}0.36 \\
\left(8.94^{* * *}\right)\end{array}$ & $\begin{array}{c}0.36 \\
\left(8.83^{* * *}\right)\end{array}$ & $\begin{array}{c}0.36 \\
\left(8.98^{* * *}\right)\end{array}$ & $\begin{array}{c}0.36 \\
\left(8.95^{* * *}\right)\end{array}$ & $\begin{array}{c}0.36 \\
\left(8.94^{* * *}\right)\end{array}$ & $\begin{array}{c}0.36 \\
\left(8.94^{* * *}\right)\end{array}$ & $\begin{array}{c}0.36 \\
\left(9.02^{* * *}\right)\end{array}$ \\
\hline X8 & $\begin{array}{c}1953.48 \\
\left(15.46^{* * *}\right)\end{array}$ & $\begin{array}{c}1954.81 \\
\left(15.45^{* * *}\right)\end{array}$ & $\begin{array}{c}1950.98 \\
\left(15.44^{* * *}\right)\end{array}$ & $\begin{array}{c}1954.41 \\
\left(15.46^{* * *}\right)\end{array}$ & $\begin{array}{c}1954 \\
\left(15.46^{* * *}\right)\end{array}$ & $\begin{array}{c}1955.42 \\
\left(15.44^{* * *}\right)\end{array}$ & $\begin{array}{c}1938.62 \\
\left(15.33^{* * *}\right)\end{array}$ \\
\hline $\mathrm{X} 7$ & $\begin{array}{l}-23,107.11 \\
\left(-5.71^{* * *}\right)\end{array}$ & $\begin{array}{l}-22,561.13 \\
\left(-4.76^{* * *}\right) \\
\end{array}$ & $\begin{array}{l}-23,144.20 \\
\left(-5.72^{* * *}\right) \\
\end{array}$ & $\begin{array}{l}-23,179.91 \\
\left(-5.73^{* * *}\right) \\
\end{array}$ & $\begin{array}{l}-23,253.52 \\
\left(-5.73^{* * *}\right) \\
\end{array}$ & $\begin{array}{l}-23,079.35 \\
\left(-5.70^{* * *}\right)\end{array}$ & $\begin{array}{l}-23,661.41 \\
\left(-5.84^{* * *}\right) \\
\end{array}$ \\
\hline X9 & $\begin{array}{c}4300.36 \\
\left(2.69^{* * *}\right)\end{array}$ & $\begin{array}{c}4304.82 \\
\left(2.70^{* * *}\right)\end{array}$ & $\begin{array}{c}4481.74 \\
\left(2.79^{* * *}\right)\end{array}$ & $\begin{array}{c}4441.88 \\
\left(2.74^{* * *}\right)\end{array}$ & $\begin{array}{c}4283.39 \\
\left(2.68^{* * *}\right)\end{array}$ & $\begin{array}{c}4299.4 \\
\left(2.69^{* * *}\right)\end{array}$ & $\begin{array}{c}4334.52 \\
\left(2.72^{* * *}\right)\end{array}$ \\
\hline $\mathrm{X} 10$ & $\begin{array}{c}5723.38 \\
\left(3.21^{* * *}\right)\end{array}$ & $\begin{array}{c}5711.66 \\
\left(3.20^{* * *}\right)\end{array}$ & $\begin{array}{c}5635.39 \\
\left(3.15^{* * *}\right)\end{array}$ & $\begin{array}{c}5764.75 \\
\left(3.22^{* * *}\right)\end{array}$ & $\begin{array}{c}5695.63 \\
\left(3.19^{* * *}\right)\end{array}$ & $\begin{array}{l}5757.29 \\
\left(3.21^{* * *}\right)\end{array}$ & $\begin{array}{c}5676.87 \\
\left(3.18^{* * *}\right)\end{array}$ \\
\hline $\begin{array}{c}\text { Added } \\
\text { Variable }\end{array}$ & & $\begin{array}{l}-818.01 \\
(-0.22)\end{array}$ & $\begin{array}{c}-0.04 \\
(-1.02)\end{array}$ & $\begin{array}{c}-0.15 \\
(-0.52) \\
\end{array}$ & $\begin{array}{l}-10.75 \\
(-0.49) \\
\end{array}$ & $\begin{array}{c}-0.02 \\
(-0.25)\end{array}$ & $\begin{array}{l}2771.16 \\
(1.92 *)\end{array}$ \\
\hline $\mathrm{R}^{2}$ & 0.5031 & 0.5028 & 0.5032 & 0.5028 & 0.5028 & 0.5028 & 0.5042 \\
\hline AIC & 22.14 & 22.14 & 22.14 & 22.14 & 22.14 & 22.14 & 22.14 \\
\hline $\mathrm{F}$ & 250.56 & 208.65 & 208.98 & 208.72 & 208.71 & 208.65 & 209.88 \\
\hline D-W & 1.7394 & 1.7384 & 1.7324 & 1.7401 & 1.7393 & 1.7394 & 1.7393 \\
\hline
\end{tabular}

Notes: ${ }^{* *}, *$ indicate $1 \%$, and $10 \%$ significance level. In extension models 1 to 6 , variables including X6, X4, X2, X5, X3, and X11 were added to the benchmark model individually.

To investigate the robustness of the benchmark model, we also estimated five extension models that incorporate the variables X6, X4, X2, X5, and X3 separately, as shown in columns 3 to 7 of Table 2 . The findings indicate that the newly included variables have little effect on the growth of township consumption. Additionally, as indicated in column 8 of Table 2, we calculated another extension model that combines the X11 variable. Although X11 seems to be important for township consumption at a $10 \%$ significance level, the primary factors affecting the development of township consumption cannot include X11 because the statistical features of extension model 6 do not differ significantly from those of the benchmark model.

It is worth noting that, according to the theoretical mechanism analysis in Figure 1, the government's inputs representing the new supply capacity for regional consumption should have a significant effect on the development of township consumption; however, the estimated results in columns 5 and 7 contradict this conclusion. That is, for townships located in underdeveloped areas, it is less reliable to support township consumption development through fiscal methods of local government.

\subsection{The Estimated Results for the Local Models and Their Calibration}

The NSM is frequently controversial because it generally ignores spatial dependency and heterogeneity. We proceed to decompose the driving factors of the township consumption development using GWR models that take into account the spatial heterogeneity among townships.

We follow the primary framework of the NSM benchmark model and first describe the constant terms of the GWR models as local variables, followed by the definition of 
some or all of the explanatory variables, including $\mathrm{X} 1, \mathrm{X} 7, \mathrm{X} 8, \mathrm{X} 9$, and $\mathrm{X} 10$. In total, 31 semi-parametric GWR models and one mixed GWR model were developed. We estimated all 32 GWR models using the GWR 4.0 software, and Table 3 contains the derived results for all models with significant parameters and optimal spatial bandwidths [44,45]. GWR 5_1, which is a mixed GWR model that treats all five explanatory variables and the constant term as local variables, is the best GWR model for decomposing the driving forces of township consumption development based on the criteria of minimal AIC and maximum $\mathrm{R}^{2}$ and GWR_F [46]. Additionally, Figure 4 depicts the estimated parameters for all six variables, including the absolute terms.

Table 3. Estimated results of parts of the GWR models.

\begin{tabular}{|c|c|c|c|c|c|c|c|c|c|c|}
\hline & Constant & $\mathrm{X} 1$ & X8 & $\mathrm{X} 7$ & X9 & $\mathrm{X} 10$ & $\mathbf{R}^{2}$ & AICc & Bandwidth & GWR F \\
\hline $\begin{array}{c}\text { GWR } \\
2 \_9\end{array}$ & $\begin{array}{c}{[-1908.9]} \\
【 6543.2 】\end{array}$ & $\begin{array}{c}0.5 \\
\left(10.47^{* * *}\right)\end{array}$ & $\begin{array}{c}1829.1 \\
\left(14.72^{* * *}\right)\end{array}$ & $\begin{array}{c}{[-6280.0]} \\
\text { 【6680.3】 }\end{array}$ & $\begin{array}{l}2833.8 \\
\left(1.90^{*}\right)\end{array}$ & $\begin{array}{c}{[9348.4]} \\
【 20,779.4 】\end{array}$ & 0.6214 & $27,273.8$ & 52 & 2.9108 \\
\hline $\begin{array}{l}\text { GWR } \\
3 \_1\end{array}$ & $\begin{array}{l}{[-1808.2]} \\
【 8044.6 】\end{array}$ & $\begin{array}{l}{[0.5]} \\
【 0.5 】\end{array}$ & $\begin{array}{l}{[1453.9]} \\
【 1648.0 】\end{array}$ & $\begin{array}{l}{[-4710.5]} \\
\text { 【4669.2】 }\end{array}$ & $\begin{array}{l}4535.9 \\
(3.58)\end{array}$ & $\begin{array}{l}5049.2 \\
(3.48)\end{array}$ & 0.7399 & $26,862.4$ & 52 & 5.2670 \\
\hline $\begin{array}{c}\text { GWR } \\
3 \_4\end{array}$ & $\begin{array}{c}{[-2181.9]} \\
\text { 【8483.7】 }\end{array}$ & $\begin{array}{l}{[0.5]} \\
【 0.5 】\end{array}$ & $\begin{array}{c}1334.1 \\
\left(11.22^{* * *}\right)\end{array}$ & $\begin{array}{l}{[-4835.6]} \\
\text { 【5822.4】 }\end{array}$ & $\begin{array}{c}{[7910.7]} \\
【 11,697.3 】\end{array}$ & $\begin{array}{c}6579.3 \\
\left(4.38^{* * *}\right)\end{array}$ & 0.7079 & $26,998.9$ & 55 & 4.3746 \\
\hline $\begin{array}{l}\text { GWR } \\
3 \_5\end{array}$ & $\begin{array}{c}{[-2057.1]} \\
【 8160.8 】\end{array}$ & $\begin{array}{l}{[0.5]} \\
【 0.6 】\end{array}$ & $\begin{array}{c}1324.6 \\
\left(11.14^{* * *}\right)\end{array}$ & $\begin{array}{l}{[-4659.2]} \\
【 5171.2 】\end{array}$ & $\begin{array}{c}3537.9 \\
\left(2.69^{* * *}\right)\end{array}$ & $\begin{array}{l}{[12,285.1]} \\
【 16,145.4 】\end{array}$ & 0.7175 & $26,967.8$ & 52 & 4.5717 \\
\hline $\begin{array}{c}\text { GWR } \\
3 \_7\end{array}$ & $\begin{array}{l}{[-2015.6]} \\
\text { 【5779.2】 }\end{array}$ & $\begin{array}{c}0.5 \\
\left(10.24^{* * *}\right)\end{array}$ & $\begin{array}{l}{[1399.3]} \\
\text { 【1686.1】 }\end{array}$ & $\begin{array}{l}{[-4435.8]} \\
\text { 【5132.9】 }\end{array}$ & $\begin{array}{c}{[8413.3]} \\
【 12,058.4\end{array}$ & $\begin{array}{c}5785.7 \\
\left(4.10^{* * *}\right)\end{array}$ & 0.7543 & $26,802.3$ & 52 & 5.7534 \\
\hline $\begin{array}{c}\text { GWR } \\
3 \_8\end{array}$ & $\begin{array}{c}{[-32690.8]} \\
\text { 【5167.8】 }\end{array}$ & $\begin{array}{c}0.4 \\
\left(9.60^{* * *}\right)\end{array}$ & $\begin{array}{c}{[-2094.6]} \\
【 1755.8 】\end{array}$ & $\begin{array}{c}{[-107,413.4]} \\
\text { 【4541.8】 }\end{array}$ & $\begin{array}{c}4031.2 \\
\left(3.22^{* * *}\right)\end{array}$ & $\begin{array}{l}{[-81,186.6]} \\
【 15,945.4 】\end{array}$ & 0.7509 & $26,812.4$ & 52 & 5.7834 \\
\hline $\begin{array}{c}\text { GWR } \\
5 \_1\end{array}$ & $\begin{array}{c}{[-2088.8]} \\
【 7060.3 】\end{array}$ & $\begin{array}{l}{[0.4]} \\
【 0.4 】\end{array}$ & $\begin{array}{l}{[1588.2]} \\
【 1624.2 】\end{array}$ & $\begin{array}{l}{[-3119.7]} \\
\text { 【4573.9】 }\end{array}$ & $\begin{array}{l}{[7089.9]} \\
【 8827.5 】\end{array}$ & $\begin{array}{c}{[8086.3]} \\
【 12,838.1 】\end{array}$ & 0.7884 & $26,730.5$ & 54 & 5.7743 \\
\hline
\end{tabular}

Notes: the above outputs were collected based on GWR 4.0. Only the outputs of the models whose optimal bandwidth is determined and estimating process runs well are listed. [] represents the mean of estimated parameters, and 【 $】$ is the corresponding robust standard deviation. ${ }^{* * *},{ }^{*}$ mean having passed the hypothesis test with a significance level of $1 \%$, and $10 \%$.

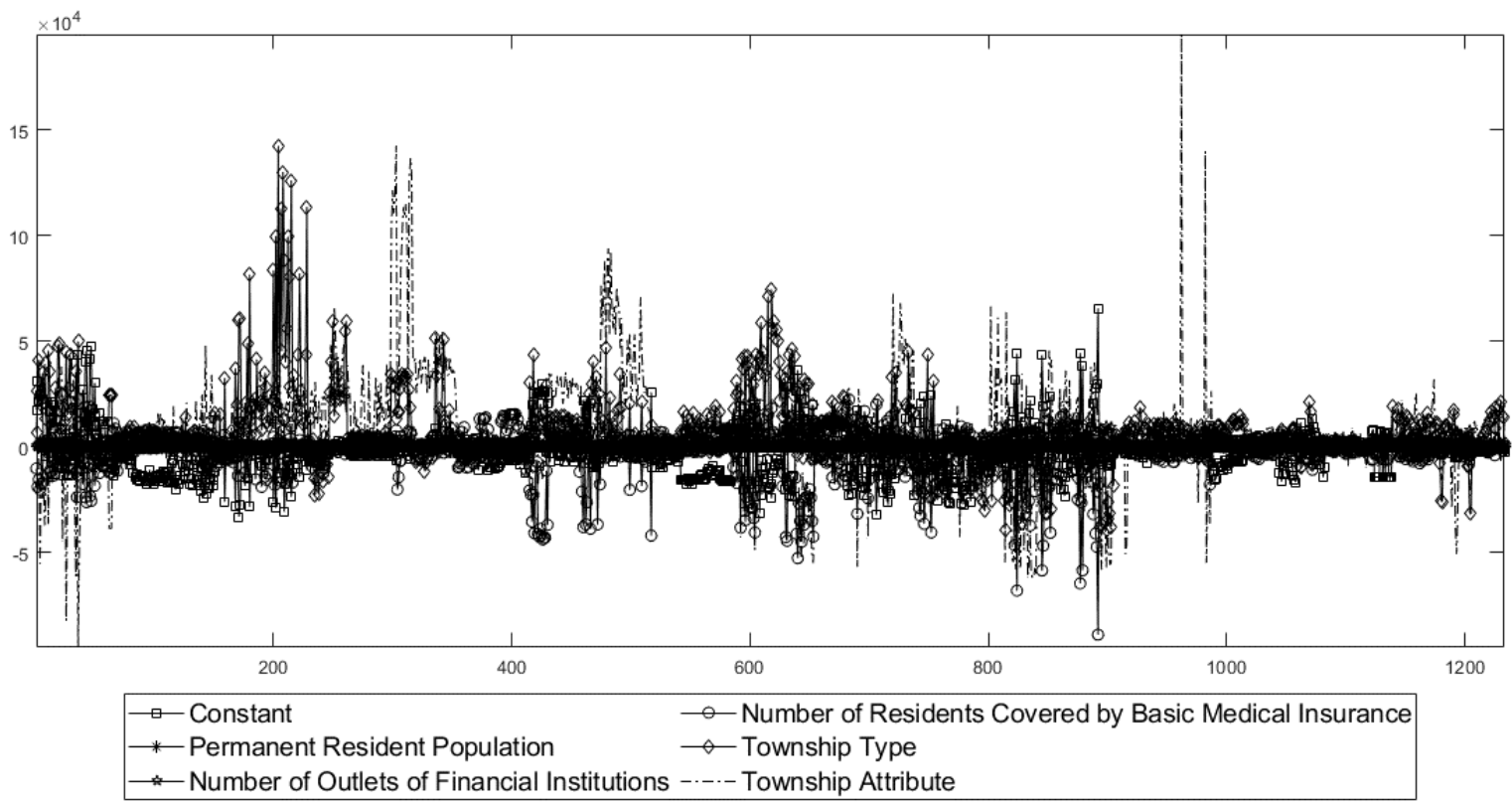

Figure 4. Estimated parameters of the best GWR model (model 5_1). 
In comparison, the results obtained by GWR 5_1 and the benchmark NSM were identical. That is, $X 7$ has a detrimental effect on the growth of township consumption, whereas $\mathrm{X} 1, \mathrm{X} 8, \mathrm{X} 9$, and $\mathrm{X} 10$ have a positive impact. There are two advantages to the GWR 5_1 model: first, the goodness of fit of GWR 5_1 is greater than that of the NSM. Second, the model of GWR 5_1 describes the rules of spatial heterogeneity, whereas the benchmark NSM does not. Additionally, the spatial heterogeneity revealed in GWR 5_1 shows that we should adopt distinct methods for consumption development in different townships.

It is worth mentioning that the optimal spatial bandwidth in the GWR 5_1 model is 54. This means that each township's consumption development will be influenced solely by its 54 nearest neighbors. It also means that in the global analysis of the driving factors' decomposition of township consumption development in Gansu, China, not all 1233 townships but just the 54 townships surrounding each town can be used to establish the elements of the spatial weight matrix. Each row in the unique spatial weight matrix used in the global analysis will contain only 54 non-zero elements, even though this matrix contains 1233 rows and 1233 columns in total, as illustrated in Figure 5.

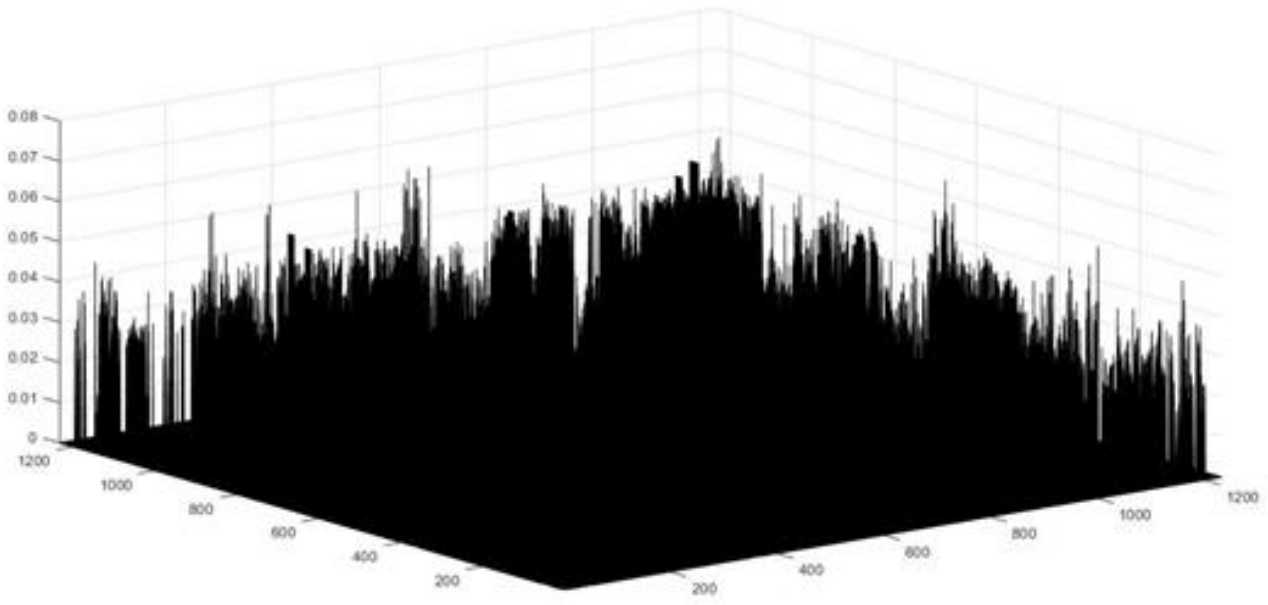

Figure 5. The unique spatial weight matrix of the spatial econometric global analysis.

\subsection{The Estimated Results of the Global Models and Their Calibration}

In this section, we continue decomposing the driving factors of the development of township consumption using spatial econometric global models that emphasize the laws of spatial spillover effects among different townships [47,48]. We calculated the GNSM and associated degradation models using MATLAB R2019a and maximum likelihood estimation, as shown in Table 4.

As demonstrated in Table 4, none of the models, including the spatial lag of $X$ model (SXL), spatial autoregressive combined model (SAC), spatial Durbin model (SDM), spatial Durbin error model (SDEM), and GNSM, are optimal since some of the variables included in these models are not statistically significant. Thus, we have to choose between the spatial autoregressive model (SAR) and spatial error model (SEM) as the optimal model. Given that the goodness of fit and log-likelihood values are similar for the SAR and SEM, the LM and robust LM tests should be employed to decide which is better.

The chi-square statistics for the LM and robust LM tests are 4.1325 and 0.0045 , respectively, when the null hypothesis is that there is no spatial autoregression term in the model, while they are 8.0072 and 3.8793, respectively, when the null hypothesis is that there is no spatial error term in the model. Thus, in the spatial econometric global analysis, the SEM is the optimal model for decomposing the driving factors of the development of township consumption in Gansu, China. 
Table 4. Estimated results of the global models based on the modified spatial weight matrix.

\begin{tabular}{|c|c|c|c|c|c|c|c|}
\hline & SAR & SEM & SXL & SAC & SDM & SDEM & GNSM \\
\hline Constant & $\begin{array}{l}15,094.36 \\
\left(3.76^{* * *}\right)\end{array}$ & $\begin{array}{l}16,020.26 \\
\left(3.96^{* * *}\right)\end{array}$ & $\begin{array}{c}-10,331.51 \\
(-0.53)\end{array}$ & $\begin{array}{l}17,611.64 \\
\left(4.18^{* * *}\right)\end{array}$ & $\begin{array}{c}-8923.12 \\
(-0.46)\end{array}$ & $\begin{array}{c}-8876.13 \\
(-0.44)\end{array}$ & $\begin{array}{c}-7357.07 \\
(-0.48)\end{array}$ \\
\hline $\mathrm{X} 1$ & $\begin{array}{c}0.36 \\
\left(8.92^{* * *}\right) \\
\end{array}$ & $\begin{array}{c}0.38 \\
\left(9.24^{* * *}\right) \\
\end{array}$ & $\begin{array}{c}0.40 \\
\left(9.47^{* * *}\right) \\
\end{array}$ & $\begin{array}{c}0.39 \\
\left(9.38^{* * *}\right) \\
\end{array}$ & $\begin{array}{c}0.40 \\
\left(9.54^{* * *}\right) \\
\end{array}$ & $\begin{array}{c}0.40 \\
\left(9.51^{* * *}\right) \\
\end{array}$ & $\begin{array}{c}0.42 \\
\left(9.72^{* * *}\right)\end{array}$ \\
\hline $\mathrm{X} 8$ & $\begin{array}{c}1937.11 \\
\left(15.39^{* * *}\right)\end{array}$ & $\begin{array}{c}1909.72 \\
\left(15.12^{* * *}\right)\end{array}$ & $\begin{array}{c}1882.46 \\
\left(14.82^{* * *}\right)\end{array}$ & $\begin{array}{c}1883.06 \\
\left(14.88^{* * *}\right)\end{array}$ & $\begin{array}{c}1878.36 \\
\left(14.85^{* * *}\right)\end{array}$ & $\begin{array}{c}1884.23 \\
\left(14.91^{* * *}\right)\end{array}$ & $\begin{array}{c}1850.25 \\
\left(14.59^{* * *}\right)\end{array}$ \\
\hline $\mathrm{X} 7$ & $\begin{array}{l}-23,822.5 \\
\left(-5.89^{* * *}\right)\end{array}$ & $\begin{array}{l}-23,514.70 \\
\left(-5.82^{* * *}\right)\end{array}$ & $\begin{array}{l}-23,107.34 \\
\left(-5.66^{* * *}\right)\end{array}$ & $\begin{array}{l}-23,222.47 \\
\left(-5.75^{* * *}\right)\end{array}$ & $\begin{array}{l}-23,171.09 \\
\left(-5.70^{* * *}\right)\end{array}$ & $\begin{array}{l}-23,092.31 \\
\left(-5.68^{* * *}\right)\end{array}$ & $\begin{array}{l}-23,425.30 \\
\left(-5.74^{* * *}\right)\end{array}$ \\
\hline X9 & $\begin{array}{c}4194.44 \\
\left(2.64^{* * *}\right)\end{array}$ & $\begin{array}{l}3743.16 \\
\left(2.35^{* *}\right)\end{array}$ & $\begin{array}{l}3531.78 \\
(2.20 * *)\end{array}$ & $\begin{array}{l}3543.10 \\
\left(2.23^{* *}\right)\end{array}$ & $\begin{array}{l}3472.07 \\
\left(2.18^{* *}\right)\end{array}$ & $\begin{array}{l}3538.01 \\
\left(2.22^{* *}\right)\end{array}$ & $\begin{array}{l}3406.12 \\
\left(2.14^{* *}\right)\end{array}$ \\
\hline $\mathrm{X} 10$ & $\begin{array}{c}5773.24 \\
\left(3.25^{* * *}\right)\end{array}$ & $\begin{array}{c}5680.96 \\
\left(3.21^{* * *}\right)\end{array}$ & $\begin{array}{c}5538.49 \\
\left(3.11^{* * *}\right)\end{array}$ & $\begin{array}{c}5547.90 \\
\left(3.15^{* * *}\right)\end{array}$ & $\begin{array}{c}5548.88 \\
\left(3.13^{* * *}\right)\end{array}$ & $\begin{array}{c}5556.86 \\
\left(3.13^{* * *}\right)\end{array}$ & $\begin{array}{c}5242.71 \\
\left(2.97^{* * *}\right)\end{array}$ \\
\hline WX1 & & & $\begin{array}{c}-0.41 \\
\left(-3.06^{* * *}\right)\end{array}$ & & $\begin{array}{c}-0.41 \\
\left(-3.05^{* * *}\right)\end{array}$ & $\begin{array}{c}-0.38 \\
\left(-2.75^{* * *}\right) \\
\end{array}$ & $\begin{array}{c}-0.49 \\
\left(-4.72^{* * *}\right) \\
\end{array}$ \\
\hline WX2 & & & $\begin{array}{c}1040.02 \\
(1.55)\end{array}$ & & $\begin{array}{l}541.45 \\
(0.72)\end{array}$ & $\begin{array}{l}918.49 \\
(1.33)\end{array}$ & $\begin{array}{l}-560.54 \\
(-0.80)\end{array}$ \\
\hline WX7 & & & $\begin{array}{c}29,675.53 \\
(1.46)\end{array}$ & & $\begin{array}{c}28,912.72 \\
(1.43)\end{array}$ & $\begin{array}{c}27,985.82 \\
(1.34) \\
\end{array}$ & $\begin{array}{c}30,039.73 \\
(1.79 *)\end{array}$ \\
\hline WX9 & & & $\begin{array}{c}19,117.61 \\
(1.85 *)\end{array}$ & & $\begin{array}{c}18,733.33 \\
\left(1.80^{*}\right)\end{array}$ & $\begin{array}{c}20,170.29 \\
(1.92 *)\end{array}$ & $\begin{array}{c}11,921.64 \\
(1.32)\end{array}$ \\
\hline WX10 & & & $\begin{array}{c}3015.96 \\
(0.24) \\
\end{array}$ & & $\begin{array}{l}639.77 \\
(0.05) \\
\end{array}$ & $\begin{array}{c}1865.26 \\
(0.15) \\
\end{array}$ & $\begin{array}{c}-2150.66 \\
(-0.19)\end{array}$ \\
\hline rho & $\begin{array}{c}0.18 \\
(1.83 *) \\
\end{array}$ & & & $\begin{array}{c}-0.23 \\
(-1.39) \\
\end{array}$ & $\begin{array}{c}0.15 \\
(1.16) \\
\end{array}$ & & $\begin{array}{c}0.60 \\
\left(4.28^{* * *}\right) \\
\end{array}$ \\
\hline lamda & & $\begin{array}{c}0.31 \\
\left(2.54^{* *}\right)\end{array}$ & & $\begin{array}{c}0.50 \\
\left(3.53^{* * *}\right)\end{array}$ & & $\begin{array}{c}0.09 \\
(0.69)\end{array}$ & $\begin{array}{c}-0.66 \\
\left(-2.58^{* *}\right)\end{array}$ \\
\hline $\mathrm{R}^{2}$ & 0.5048 & 0.5065 & 0.5080 & 0.5087 & 0.5087 & 0.5082 & 0.5160 \\
\hline $\log (\mathrm{L})$ & $-13,644.92$ & $-13,643.5$ & $-13,638.2$ & $-13,642.9$ & $-13,637.5$ & $-13,637.9$ & $-13,635.5$ \\
\hline
\end{tabular}

Note: the above outputs were collected based on MATLAB R2019a and spatial econometric toolbox jplv7. () represents T-statistic, ${ }^{* * *}, * *$, and ${ }^{*}$ mean having passed the hypothesis test with a significance level of $1 \%, 5 \%$, and $10 \%$.

It is worth emphasizing that the coefficients of variables in the SEM represent their marginal effects on the dependent variable; we do not have to resolve them into direct, indirect, and total effects as other spatial econometric global models do throughout the data generation process [33]. As indicated in column 3 of Table 4, five elements, including X1, $X 7, X 8, X 9$, and $X 10$, are the primary driving forces behind the development of township consumption in underdeveloped areas, with $X 7$ having a negative impact and the other four factors having a positive impact. A study conducted in Indonesia [49] stated that the effect of increasing population density in urban or rural areas on per capita household consumption spending might be either positive or negative, depending on the household's human capital. Another study [50] reaffirmed that rural retailing services varied by location and the attributes of the township. This result is consistent with those obtained from the benchmark and optimal GWR models. Additionally, the spatial autoregression term has a coefficient of 0.31 in the spatial econometric global analysis, indicating a positive spatial spillover effect on the development of township consumption in underdeveloped areas.

\section{Conclusions}

This paper presented the decomposition of the driving forces of the township consumption development in underdeveloped areas such as Gansu Province, China. The 
study took total retail sales of consumer goods as a response variable to evaluate the effect of decomposition of township consumption development on explanatory variables including economic and policy characteristics. This study used data from 1233 townships from the third national agricultural census of Gansu, China. The data were analyzed using an integrated framework of the GWR model and a global spatial econometric model. Three significant findings were revealed. First, we can integrate the GWR models and global models through consistent settings of the elements of the spatial weight matrices. In comparison, the GWR models emphasize spatial heterogeneity, while the global models emphasize the laws of spatial dependence and spatial spillover effects. Second, both the optimal GWR model and the optimal global model of the SEM indicate that the primary factors influencing the development of township consumption in underdeveloped areas are permanent resident population, the ratio of residents covered by basic medical insurance, number of outlets of financial institutions, township type, and township attribute. Among them, the ratio of residents covered by basic endowment has a negative impact, while permanent population, the ratio of residents covered by basic medical insurance, township types, and township attributes had a positive effect on township consumption. Third, other factors, such as government revenue, public expenditure, township total assets, the trading volume of the commodity market, the ratio of residents covered by basic endowment insurance, and old revolutionary areas, border areas, and ethnic minority areas, had no significant impact on the township consumption development in underdeveloped regions.

Although the study has made substantial contributions, several limitations can be addressed in future research. China is a large country with a cosmopolitan population. Rural communities come in a variety of shapes and sizes, and there is no one-size-fits-all rural rehabilitation program. Future research should explore additional data to develop a clear picture of township consumption. It is also advised that additional predicators be included in order to completely address rural area issues. The authors anticipate using the findings to further investigate the dynamics at work in this part of China's rural revitalization processes and the spatial planning conclusions that will be drawn.

\section{Policy Recommendations}

The following policy recommendations are suggested in light of the study's findings for expanding township consumption in underdeveloped areas.

First, encourage the population aggregating in townships. The population scale is the most crucial factor in the development of township consumption, and the aggregation of the community can promote consumption development through the scale effects and the demonstration effects. It means a bigger scale of use if there are more residents in the townships. Meanwhile, there will also be an exemplary role for the others if some of the residents begin to consume. The local government should encourage rural people's regional urbanization by implementing a preferential demolition policy for rural homes, boosting agricultural collective commercial construction land, and regulating the price of real estate in townships. Additionally, the local government should ensure that surplus labor is used locally by strongly supporting the development of township enterprises and assisting migrant workers returning to their hometowns in starting businesses through the implementation of advantageous tax and land policies. Moreover, the local government should make significant efforts to boost township consumption by expanding medical care, old-age care, education, and cultural and recreational opportunities.

Second, promote extensions of the urban functions of the counties to the townships nearby. Generally speaking, a higher level of infrastructure results in better consumption, and there will usually be better infrastructures if the towns are defined as critical towns by the superior government or close to the seat of the superior county government. The superior county government can improve the level of infrastructure construction in the townships nearby by both extending the administrative map of the county and establishing new economic zones. Meanwhile, the connectivity can also be strengthened by constructing 
more traffic infrastructure and increasing the number and density of vehicles from the county to the surrounding townships.

Third, strengthen the construction of supporting platforms and carriers for the development of the township consumption. The development of township consumption in underdeveloped areas is inseparable from the platform construction. It is necessary to strengthen the wholesale markets for agricultural products and form a relatively complete rural market system. Additionally, townships can develop characteristic agriculture and leisure agriculture by building unique towns based on their scenic spots, rural tourism, and health and leisure resources. In addition, municipalities can increase the consumption supply capacity by cultivating industrial clusters through mergers and reorganization, and investment attraction.

Fourth, strengthen the financial supports for the township consumption development. The impact of the development of finance is self-evident in township consumption development. Townships can obtain necessary financial supports in consumption development by actively connecting with the China Development Bank and Agricultural Development Bank of China. Additionally, townships can attract leading institutions, such as the Agricultural Bank of China, Postal Savings Bank of China, and local rural credit cooperatives, to build up outlets and strengthen their financial supports for local consumption development. In addition, townships can also encourage establishing village banks by tax breaks, subsidies, and other incentives, and ensure they provide more financial services for consumers.

Author Contributions: Conceptualization, Q.Z.; Q.F.; P.Z.; methodology, Q.Z.; Q.F.; P.Z.; software, Q.Z..; Q.F.; formal analysis, Q.Z.; P.Z.; investigation, Q.Z.; P.Z.; resources, Q.Z..; data curation, P.Z.; writing—original draft preparation, Q.Z.; Q.F.; P.Z.; writing—review and editing, Q.Z.; Q.F.; P.Z.; visualization, Q.F.; supervision, Q.Z..; project administration, Q.Z.; funding acquisition, P.Z. All authors have read and agreed to the published version of the manuscript.

Funding: This work was sponsored in part by the National Social Science Foundation of China (19XMZ095).

Institutional Review Board Statement: Not Applicable.

Informed Consent Statement: Not Applicable.

Data Availability Statement: The data presented in this study are available on request from the corresponding author.

Conflicts of Interest: The authors declare that they have no conflict of interest.

\section{References}

1. Long, H.; Li, Y.; Liu, Y.; Woods, M.; Zou, J. Accelerated restructuring in rural China fueled by 'increasing vs. decreasing balance' land-use policy for dealing with hollowed villages. Land Use Policy 2012, 29, 11-22. [CrossRef]

2. Zhang, Y.; Westlund, H.; Klaesson, J. Report from a Chinese Village 2019: Rural Homestead Transfer and Rural Vitalization. Sustainability 2020, 12, 8635. [CrossRef]

3. Liu, Y.; Li, Y. Revitalize the world's countryside. Nat. News 2017, 548, 275. [CrossRef]

4. Liu, J.; Liu, Y.; Yan, M. Spatial and temporal change in urban-rural land use transformation at village scale-A case study of Xuanhua district, North China. J. Rural Stud. 2016, 47, 425-434. [CrossRef]

5. Hu, C.T.; Myrdal, J.; Kessle, G.; Michael, M. Report from a Chinese Village. Political Sci. Q. 1966, 81, 164. [CrossRef]

6. Liu, Y.; Wang, Y. Rural land engineering and poverty alleviation: Lessons from typical regions in China. J. Geogr. Sci. 2019, 29, 643-657. [CrossRef]

7. Liu, Y.; Zang, Y.; Yang, Y. China's rural revitalization and development: Theory, technology and management. J. Geogr. Sci. 2020, 30, 1923-1942. [CrossRef]

8. Unger, J.; Chan, A. Inheritors of the boom: Private enterprise and the role of local government in a rural South China township. China J. 1999, 42, 45-74. [CrossRef]

9. Deng, X.; Zhang, F.; Wang, Z.; Li, X.; Zhang, T. An Extended Input Output Table Compiled for Analyzing Water Demand and Consumption at County Level in China. Sustainability 2014, 6, 3301-3320. [CrossRef]

10. Qi, J.; Li, W.; Wang, Z.; Fang, H. Measurement and Path Selection of Rural Development Level in Enclave Areas: A Case Study of Jingyuan County, Gansu Province. Sustainability 2021, 13, 9904. [CrossRef] 
11. Liao, F.H.; Wei, Y.D. Dynamics, space, and regional inequality in provincial China: A case study of Guangdong province. Appl. Geogr. 2012, 35, 71-83. [CrossRef]

12. Martin, S. Advanced Industrial Economics 2E [M]. 2003. Available online: https://www.krannert.purdue.edu/faculty/smartin/ aie2/aie2ans.pdf (accessed on 3 November 2021).

13. Nicholson, W.; Snyder, C.M. Microeconomic Theory: Basic Principles and Extensions; Cengage Learning: Mason, OH, USA, 2012.

14. An, H.; Xu, J.; Ma, X. Does technological progress and industrial structure reduce electricity consumption? Evidence from spatial and heterogeneity analysis. Struct. Chang. Econ. Dyn. 2020, 52, 206-220. [CrossRef]

15. Vries, J. The Industrious Revolution: Consumer Behavior and the Household Economy, 1650 to the Present; Cambridge University Press: Cambridge, UK, 2008.

16. Sun, T.; Wu, G. Consumption patterns of Chinese urban and rural consumers. J. Consum. Mark. 2004, 21, 245-253. [CrossRef]

17. Abed, O.; Bellemans, T.; Janssens, G.; Patil, B.; Yasar, A.; Janssens, D.; Wets, G. A Micro Simulated and Demand Driven Supply Chain Model to Calculate Regional Production and Consumption Matrices. Procedia Comput. Sci. 2013, 19, 404-411. [CrossRef]

18. Solér, C.; Koroschetz, B.; Salminen, E. An infrastructural perspective on sustainable consumption-Activating and obligating sustainable consumption through infrastructures. J. Clean. Prod. 2020, 243, 118601. [CrossRef]

19. Daitoh, I. Control. Productive consumption and population dynamics in an endogenous growth model: Demographic trends and human development aid in developing economies. J. Econ. Dyn. Control 2010, 34, 696-709. [CrossRef]

20. Bayer, C.; Rendall, A.D.; Wälde, K. The invariant distribution of wealth and employment status in a small open economy with precautionary savings. J. Math. Econ. 2019, 85, 17-37. [CrossRef]

21. Gradín, C.; Wu, B. Income and consumption inequality in China: A comparative approach with India. China Econ. Rev. 2020, 62, 101463. [CrossRef]

22. Marrinan, J. Finance. Government consumption and private consumption correlations. J. Int. Money Financ. 1998, 17, 615-636. [CrossRef]

23. Crewe, L.; Beaverstock, J. Fashioning the city: Cultures of consumption in contemporary urban spaces. Geoforum 1998, 29, 287-308. [CrossRef]

24. Boehm, C.E. Government consumption and investment: Does the composition of purchases affect the multiplier? J. Monet. Econ. 2020, 115, 80-93. [CrossRef]

25. Brueckner, J.K. Infrastructure financing and urban development: The economics of impact fees. J. Public Econ. 1997, 66, 383-407. [CrossRef]

26. Foster, S.A.; Gorr, W.L. An Adaptive Filter for Estimating Spatially-Varying Parameters: Application to Modeling Police Hours Spent in Response to Calls for Service. Manag. Sci. 1986, 32, 878-889. [CrossRef]

27. Brunsdon, C.; Fotheringham, S.; Charlton, M. Geographically weighted regression. J. R. Stat. Soc. Ser. D 1998, 47, 431-443. [CrossRef]

28. Mennis, J. Mapping the Results of Geographically Weighted Regression. Cartogr. J. 2006, 43, 171-179. [CrossRef]

29. Ruppert, D. Empirical-bias bandwidths for local polynomial nonparametric regression and density estimation. J. Am. Stat. Assoc. 1997, 92, 1049-1062. [CrossRef]

30. Varga, A. University Research and Regional Innovation: A Spatial Econometric Analysis of Academic Technology Transfers; Springer Science \& Business Media: Berlin/Heidelberg, Germany, 1998; Volume 13.

31. Elhorst, J.P. Spatial Econometrics from Cross-Sectional Data to Spatial Panels; Springer: Berlin/Heidelberg, Germany, 2014.

32. Huang, H.; Wang, F.; Song, M.; Balezentis, T.; Streimikiene, D. Green innovations for sustainable development of China: Analysis based on the nested spatial panel models. Technol. Soc. 2021, 65, 101593. [CrossRef]

33. Lesage, J.; Pace, R.K. Introduction to Spatial Econometrics; CRC Press: Boca Raton, FL, USA, 2009.

34. LeSage, J.P.; Pace, R.K. Spatial econometric models. In Handbook of Applied Spatial Analysis; Springer: Berlin/Heidelberg, Germany, 2010; pp. 355-376.

35. Pace, R.K.; LeSage, J.P.; Zhu, S. Spatial Dependence in Regressors and its Effect on Performance of Likelihood-Based and Instrumental Variable Estimators; Emerald: Bingley, UK, 2012; pp. 257-295. [CrossRef]

36. Getis, A.; Aldstadt, J. Constructing the spatial weights matrix using a local statistic. Geogr. Anal. 2004, 36, 90-104. [CrossRef]

37. Qu, X.; Lee, L.-F. Estimating a spatial autoregressive model with an endogenous spatial weight matrix. J. Econ. 2015, 184, 209-232. [CrossRef]

38. Bhattacharjee, A.; Jensen-Butler, C. Estimation of the spatial weights matrix under structural constraints. Reg. Sci. Urban Econ. 2013, 43, 617-634. [CrossRef]

39. Kelejian, H.H.; Piras, G. Estimation of spatial models with endogenous weighting matrices, and an application to a demand model for cigarettes. Reg. Sci. Urban Econ. 2014, 46, 140-149. [CrossRef]

40. Minard, P. Institutions and China's comparative development. arXiv 2020, arXiv:2001.02804.

41. Li, H.; Xu, X.; Li, S. Does Entrepreneurship Contribute to Innovation Performance When Considering Spatial Spillover Effects? Evidence from the Automobile Industrial Cluster in China. SAGE Open 2020, 10. [CrossRef]

42. Yang, W.; Fan, B.; Desouza, K. Spatial-temporal effect of household solid waste on illegal dumping. J. Clean. Prod. 2019, 227, 313-324. [CrossRef]

43. Romdhonah, Y.; Fujiuchi, N.; Takahashi, N.; Nishina, H.; Takayama, K. Empirical Model for the Estimation of Whole-plant Photosynthetic Rate of Cherry Tomato Grown in a Commercial Greenhouse. Environ. Control Biol. 2021, 59, 117-124. [CrossRef] 
44. Zhu, C.; Zhang, X.; Zhou, M.; He, S.; Gan, M.; Yang, L.; Wang, K. Impacts of urbanization and landscape pattern on habitat quality using OLS and GWR models in Hangzhou, China. Ecol. Indic. 2020, 117, 106654. [CrossRef]

45. Tang, J.; Gao, F.; Liu, F.; Zhang, W.; Qi, Y. Understanding Spatio-Temporal Characteristics of Urban Travel Demand Based on the Combination of GWR and GLM. Sustainability 2019, 11, 5525. [CrossRef]

46. Li, C.; Li, F.; Wu, Z.; Cheng, J. Exploring spatially varying and scale-dependent relationships between soil contamination and landscape patterns using geographically weighted regression. Appl. Geogr. 2017, 82, 101-114. [CrossRef]

47. Lesage, J.P.; Fischer, M.M. Spatial Growth Regressions: Model Specification, Estimation and Interpretation. Spat. Econ. Anal. 2008, 3, 275-304. [CrossRef]

48. Elhorst, P.; Vega, S.H. On Spatial Econometric Models, Spillover Effects, and W. 2013. Available online: http://hdl.handle.net/10 419/123888 (accessed on 3 November 2021).

49. Liu, Y.; Yamauchi, F. Population density, migration, and the returns to human capital and land: Insights from Indonesia. Food Policy 2014, 48, 182-193. [CrossRef]

50. Paddison, A.; Calderwood, E. Rural retailing: A sector in decline? Int. J. Retail Distrib. Manag. 2007, 35, 136-155. [CrossRef] 